\title{
Childminders' Close Relationship Model of praxis: an ecocultural study in Ireland
}

\author{
Miriam O'Regan \\ Technological University Dublin, miriam.oregan@tudublin.ie \\ Ann Marie Halpenny \\ Technological University Dublin, Annmarie.Halpenny@tudublin.ie \\ Nóirín Hayes \\ Trinity College Dublin, Ireland, hayesn@tcd.ie
}

Follow this and additional works at: https://arrow.tudublin.ie/aaschlanart

Part of the Early Childhood Education Commons

\section{Recommended Citation}

O'Regan, M., Halpenny, A.M. \& Hayes, N. (2020). Childminders' Close Relationship Model of praxis: an ecocultural study in Ireland. European Early Childhood Education Research Journal, vol. 28, no. 5, pg. 675-689. doi:10.21427/a1k4-q735

This Article is brought to you for free and open access by the Languages at ARROW@TU Dublin. It has been accepted for inclusion in Articles by an authorized administrator of ARROW@TU Dublin. For more information, please contact arrow.admin@tudublin.ie, aisling.coyne@tudublin.ie,gerard.connolly@tudublin.ie. Funder: Irish Research Council

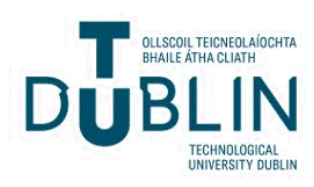




\section{Childminders' Close Relationship Model of Praxis: An ecocultural study in Ireland}

\section{Miriam O'Regan ${ }^{\mathrm{a} *}$, Ann Marie Halpenny ${ }^{\mathrm{b}}$ and Nóirín Hayes ${ }^{\mathrm{c} .}$}

School of Languages, Law and Social Sciences, Technological University Dublin,

Grangegorman, Dublin, Ireland.

${ }^{b}$ School of Languages, Law and Social Sciences, Technological University Dublin, Grangegorman, Dublin 7, Ireland.

${ }^{c}$ Professor Emerita, Technological University Dublin, and Visiting Professor, School of Education, Trinity College Dublin.

*corresponding author e-mail: D13128461@mytudublin.ie

http://orcid.org/0000-0001-9272-5815

This research is funded by the Irish Research Council with Childminding Ireland as enterprise partner. Grant number: EPSPG/2016/150 


\section{Childminding Praxis: Findings from an ecocultural study in Ireland}

The present study seeks to address the dearth of research focussed on childminding (family daycare or family childcare) in Ireland, despite its significant role in national childcare provision. One overarching aim was to explore childminders' cultural models of praxis and pedagogy in the Irish context. This research was conducted within the theoretical framework of Ecocultural Theory (ECT) (Weisner 1993, 2002), referencing concepts in Attachment Theory, in the context of historical and current policy in Ireland, Europe and the US over the last 30 years. A mixed method approach was adopted using the Ecocultural Family Interview for Childminders (EFICh) protocol, which included holistic ratings, field notes, photographs taken by participants, and a case study survey. This article describes one cultural model identified among childminders in this study, a Close Relationship Model of praxis in a home-from-home environment, prioritising love and fun in mixed age childcare, developing enduring relationships in an extended childminding family. To effectively engage professional childminders in Ireland, any proposed system of regulation, support, and education should be aligned with this cultural model to maximise the benefits of childminding for children's outcomes in the $21^{\text {st }}$ century.

Keywords: Childminding (family daycare, family childcare); Ecocultural Theory; Cultural Models; Attachment, Close Relationships model. 


\section{Introduction: Childminding in Ireland}

Home-based childcare, paid and unpaid, provides the largest source of nonparental childcare in Ireland (29\%): an estimated 10\% of children in Ireland from infancy to 12 years of age receive care from paid professional childminders, and a further $3 \%$ of children are with paid relatives (CSO 2017). However, Early Years Regulations (DCYA 2016) exempt childminders caring for three or fewer unrelated preschool children, and the new School Age Services register also exempts childminders caring for up to six children of any age (DCYA 2018b), effectively excluding almost all paid childminders from the national ECEC system of support, regulation and inspection. In 2019, out of an estimated 19,000-35,000 childminders, (DCYA 2018a, 2019) there were 81 childminders registered with Tusla, the national body responsible for the registration and inspection of childcare. There have been many calls for the proportionate regulation of childminding, appropriate for a lone worker in a home based setting (Daly 2010; Start Strong 2012). As the Government moves towards mandatory regulation of paid childminding (Govt. of Ireland 2019), the unique nature of childminding needs to be documented in order to develop a sustainable regulatory and support system that honours this particular form of Early Childhood Education and Care [ECEC].

\section{Research into Childminding}

The use of childminders is widespread internationally; however, childminding remains relatively under-researched in scope and in focus (Urban et al. 2011; Ang, ,Brooker, and Stephen 2016), and very few studies document childminding practice on the ground (Tonyan, Paulsell, and Shivers 2017). Landmark studies focused on childminding (Mooney and Statham 2003) have identified indicators of quality in childminding settings, such as regulation (Davis et al. 2012), education (Bauters and 
Vandenbroeck 2017), employment status (Letablier and Fagnani 2009), and support systems (Brooker 2016). However, most childminding in Europe and the USA still operates in the informal sector (Child in Mind 2017; Tonyan, Paulsell, and Shivers 2017). Moreover, researchers consider that few quality measures have effectively captured the potential strengths of childminding (Bromer, McCabe, and Porter 2013 ).

\section{Theoretical Framework}

In order to document the daily lives and routines of childminders in Ireland Ecocultural Theory (ECT) (Tonyan 2012, 2015), was selected as an appropriate theoretical framework. From an ecocultural perspective, childminding constitutes "a home-based ecological niche in which multiple families (i.e. childminder, children, childminder's own family, and children's families) work together in raising children" (Tonyan and Nuttall 2014, 119). Since the culture of early care is not an abstract concept, but becomes visible in everyday activities (Gillen, 2014; Rogoff et al., 2007), the lens of daily routine permits the description of the cultural models (Holland and Quinn 1987; Weisner and Hay 2015) underpinning childminders' practice (Tonyan 2015).

\section{Cultural Models}

Cultural models may be defined as "presupposed, taken-for-granted models of the world that are widely shared ... by the members of a society..." (Holland and Quinn 1987, 4). They are situated in real physical and material conditions of a particular local context, or ecology (Tonyan 2015, 2017; Tonyan and Nuttall 2014) and are shaped by the beliefs seen in religious practice, ceremonies, art, music, games and play (Weisner 1997; Weisner and Hay 2015). In regards to raising children, scripts and routines instantiate cultural models and values in socially organized ways, along with material 
and symbolic tools used to achieve these local ideals (Rogoff et al. 2007). The cultural models involved in childminding are closely related to the cultural scripts that guide parents' childrearing practices, which form developmental pathways by which children learn for adaptation to life (Weisner 2002).

\section{Methodology}

The research reported in this article forms part of a wider study, using a semistructured interview, the Ecocultural Family Interview for Childminders (EFICh), specifically adapted to capture the ecocultural features of childminding. The original Ecocultural Family Interview (EFI) (Weisner and Bernheimer 2004) focussed on a family's daily routines as these develop within the resources and constraints of their ecology based on beliefs and values within the family's culture. Since a childminding niche contains multiple families and operates as a business, the EFI was adapted for use in childminding research in California (CCCRP 2014; Tonyan 2015, 2017) and further tailored for the present study regarding Hiberno-English usage (e.g. family childcare $=$ childminding) as well as the Irish ECEC context in collaboration with Elena Paredes from the Californian Child Care Research Partnership at California State University Northridge (Paredes et al. 2018).

The EFI research instrument has three main components: first, the semistructured, conversational interview; second, childminder photographs illustrating their daily practice used as prompts in the interview, and thirdly, field notes of observations of the home and the interactions. In the EFICh protocol, a background survey also gathered information about the family's economic circumstances, the childminder's reported levels of agency, their education level, and views on early childhood.

Two visits were made to each setting: an initial visit to explain the research, deliver the background survey, and conduct a brief observation, and a second visit, 
during which an EFICh interview of approximately 1-1.5 hours was conducted. In total, 17 childminders participated in the research: two were registered with Tusla, the national agency responsible for childcare; 15 were members of Childminding Ireland, the national membership organisation for professional childminders. All participants were female, and over 70\% held the national standard qualification for centre-based ECEC practitioners, a 400-hour post-secondary certificate.

Subsequently, the data were coded using Dedoose ${ }^{\circledR}$, a web-based application for analyzing mixed method research with text, photos, audio, videos, and spreadsheet data (Salmona, Lieber, and Kaczynski 2019). This allowed for a qualitative analytic process of structured discovery, "during which analytic strategies remained open to unexpected processes and patterns while focusing on project-specific topics" (Weisner 2014, 167). This analytic approach explores patterns through close, iterative listening, reading, and observing of the sample data, guided by project specific questions. In addition, holistic ratings were also completed for each childminder based on what they valued, enacted and evaluated in relation to four thematic areas: Cultural Models, Sustainability of Daily Routines, Service Needs and Use and Quality Improvement, Advocacy, \& Complexity, with each rating justified by supporting vignettes drawn from the field notes or the interview.

Using the protocols developed for the California Child Care Research Partnership by Tonyan et al (2015; CCCRP 2014), childminders were initially rated according to fit with two cultural models identified in California, Close Relationships and School Readiness (Tonyan 2017) as High, Medium or Low. To receive a High rating, the childminder must value a model in what she says, enact it in her daily routine activities, and see (or evaluate) its impact on the children's outcomes in some way. A Medium rating means the childminder partially values, enacts or sees that particular 
model, while a Low rating means that there is little or no evidence of valuing, enacting, or seeing the model.

\section{Ethical Considerations}

This research was approved by the Ethics Committee of TU Dublin in accordance with its policies and procedures. There were no significant ethical issues, since the core research involved interviews with adult childminders, and no observations of individual children were conducted. Photographs were shared with parental consent, and any identifying features were removed to ensure anonymity.

\section{Limitations of study}

Since the research was conducted with a small, self-selecting sample of professionalised childminders, it may reflect primarily the views of childminders who were more confident about coming forward to participate. Caution should be exercised in applying the findings to Irish childminders in general. This investigation is the work of a sole researcher, and the possibility of interpretation bias must be acknowledged.

\section{The Close Relationships Model of praxis}

The most prevalent cultural model identified among childminders in this study was a Close Relationship Model, similar to that identified in California, with all 17 respondents scoring a HIGH rating. A substantial number of sub-themes contributed to this model of Close Relationships, including additional sub-themes reflecting the cultural values and scripts enacted in childminding in the Irish context. In particular, analysis highlighted a value for long term, enduring relationships, beyond the boundaries of the childcare arrangement, and a conceptualisation of the childminding service as extended family. 


\section{Love and affection}

A key finding in this study was the pervasiveness of references to emotional warmth and affection of relationships between childminders and the children in their care. When describing the emotionality of their relationships with the children, childminders openly used the language of love and affection alongside terms derived from attachment theory (Bowlby 2007; Page 2011, 2018).

Narratives included many references to the physical and emotional closeness which evolves through interaction with the children, for example: "You can never spoil a child ... keep them up, and huggle them, and cuddle them." -Marianne.

This closeness was frequently described as a 'bond', referring to secure interpersonal relationships developed over time as infant and primary caregiver interact (Bowlby, 1969, 1984). Such supportive relationships influence children's healthy development long term, contributing to optimal cognitive and social emotional development for infants and toddlers (Sroufe 2005).

A key feature perceived to facilitate the development of close bonds was the intimacy and familiarity associated with the home setting, where close interactions with the same children occur on a daily basis. These close bonds were identified as a motivating factor in choosing to childmind, as this quotation exemplifies:

I'd say one (reward) is the bond that you get with the children that you're looking after because it's a lot closer than say when you're in a crèche where it's bigger and you might not be with the same children all the time. -Shona.

For many participants, small group size was key to developing close bonds. One childminder described how she grew her service to accommodate up to 40 children in a full day care service. However, after two years, she realised that managing a service had distanced her significantly from what she called the essence of childminding: "a 
close bond with a few children in a home environment." -Paula. This description reflects the meaning systems from which childminder participants drew to explain their childcare practices.

Findings also highlighted the central role of regular, warm and meaningful interactions with the child in terms of developing this emotional bond. The unique quality of interactions which childminders can achieve with very young infants one-toone is captured in the following quote:

And he just loves if you talk to him, and he'll talk back to you. He gives it loads, and he just, he really enjoys that interaction. And he loves it and it's just beautiful. It's wonderful. I love it. -Ciara.

The value of slow-paced, unhurried time in building these interactions was underlined, with childminders emphasizing the time they spent talking with children, while making things, and growing things, and going places. One childminder, who cared for school age children, emphasised the importance of supporting communication by noticing a child's mood, listening, and creating space for a child to express themselves, as the following illustrates:

But when I'm here, I can say to one, 'Go and watch TV, I want to work with your sister on one-to-one.' And then you will really get out if a child has behaviour problems, you will be able to know, okay, what is happening here? - Cynthia

The value of such one-to-one interactions is highlighted in the Irish early years' quality framework, Síolta (CECDE 2006), as the quality of young children's experience is closely linked to interactions between child and caregiver. The rich interactions described and observed holistically on visits are in keeping with Bronfenbrenner and Morris's concept of proximal processes in the Bio-Ecological model: "To be effective, 
the interaction must occur on a fairly regular basis over extended periods of time." $(2006,167)$.

\section{Fun and happiness}

Happiness is generally understood as a basic indicator of subjective well-being (Koch 2018; Garrick et al. 2010), related to self-fulfilment and development. In this research, constructs of fun and happiness in children's everyday lives were emphasised throughout the narratives, along with childminders' role in generating such fun.

For the childminders in the present study, play was mainly about fun; it was not seen or described as a means to another end, such as learning a concept or skill, but rather the emphasis was on how meaningful relationships grow in an atmosphere of play and fun. Several childminders mentioned how much they loved hearing children's happy laughter in their homes, as one of the most personally rewarding aspects of childminding: "I think it's to see these happy children. Like they are so delighted, and they don't want to go home in the evenings..." - Katriina

Having fun was seen as the basis for the child's happiness and well-being. According to Aistear, (NCCA 2009) the Irish early childhood curriculum framework, well-being consists of two main elements: psychological well-being (i.e. feeling and thinking) and physical well-being. For one childminder, this translated into some simple all-encompassing house rules: "My only rules are like: 'You're here to have fun. You're here to have fun, and you're here to play,' you know?" -Marianne

Such close attachment relationships, along with routine, are foundational to children's well-being, and are also among the most widely observed protective factors for individual resilience in children (Masten 2014). One childminder highlighted this in particular, by describing the positive impact of their consistent attachment relationship on children's resilience, during a period of family breakdown. 


\section{Interactions with parents}

Partnership between parents and early educators is widely agreed to ensure best outcomes for children (CECDE 2006). For childminders in the present study, this involved ensuring that parents were happy with the childminding service as far as possible: "I don't think that I will change anything because kids are happy, parents are happy, and I'm happy, so I don't think .... there is no point to change anything like..." Katriina. A recent survey of parents in Ireland $(n=3,630)$ also showed that over $93 \%$ were satisfied or very satisfied with their childminder (DCYA 2018a).

Many participants discussed the process of developing a healthy dynamic in relationships with parents, communicating via daily diaries, emails and conversations at the door, as well as sending regular photographs of children at play with WhatsApp, for example. However, partnership with parents also included building supportive relationships mothers finding it difficult to leave their child to go to work:

...a very anxious Mum at the start, so she needed a lot of reassurance, tears in the hallway from her and from the child. ... just giving them a lot of time, both in the morning and the evening especially, just helps to create the relationship and it really works. - Rianne.

Participants described building supportive relationships with the parents through this vulnerability met with loving support, and mutual open, honest communication in negotiating evolving, very personal relationships (Garrity and Canavan 2017).

However, relational conflict with parents was also a key challenge identified by many participants. Since childminders typically work alone at home, not in a centre with colleagues, close relationships can sometimes hinder effective business practice. Many participants acknowledged how difficult it was to broach certain subjects, money in particular, even if a contract or working agreement was in place. 


\section{Enduring relationships}

A significant finding in this study, in contrast to findings in California, was the potential for enduring relationships to evolve between childminder, child and parents. Bowlby $(1988,32)$ distinguishes between displays of "episodic ... attachment behaviours" and "enduring attachments ... to particular others" involving love and closeness between two people achieved through reliable, consistent, warm exchanges over time.

Many participants described such long term relationships with children and family, often using the language of deep attachment with the children in their care. Experienced childminders described caring for a child for up to nine years or working with the same family over 12 years. These enduring relationships are well illustrated by the following quotation: "I have kids coming back to me... I've had kids, who have had their kids, you know, and they'll go, 'Oh!', they'll ring me up and they said, 'Any chance you're free? That's lovely, that's rewarding." -Marianne.

Notably, for most participants, childminding was conceptualised as being more than just "a job" (Garrity and McGrath 2011, 78). Certain activities characterised the unique nature of the relationships between childminders and children, for example, taking children out to family events or caring for them outside working hours, unpaid, in order to spend more time with these special minded children.

For some childminders, this depth of attachment could cause separation difficulties when a child left the setting. One childminder described her grief as follows: "But anytime a child leaves me here, I'm bawling when they're going away, it's desperate, it's awful, desperate all together... You get fierce attached, ... because they're like your own...when they're around. - Cathy. 
These findings suggest that relationships between childminders, minded children and their families go beyond the type of close relationships described by most childminders in California and may also go beyond the type of relationship developed in most forms of ECEC provision in Ireland.

\section{Extended Family Belonging}

Many participants described their minded children as part of their family and conceptualised their care in terms of extended family, sometimes explicitly: "I think well, you see, you grow to, you grow to love the children, and they become part of nearly your extended family." - Chloe. Related sub-themes included prioritising the wellbeing of their own family, the development of close sibling-like relationships, whole family involvement in the service, and the responsibility of shaping children's social and emotional development. As Aistear (NCCA 2009) highlights, relationships with family members, other adults and children play a key role in building a child's identity, creating an important foundation for learning and development.

Most participating childminders started childminding because they wanted to care for their own children at home, while making a contribution to the family income, a motivation identified in previous research (Brooker, 2016; Morrissey \& Banghart, 2007; Tonyan \& Nuttall, 2014). Given this motivation, childminders seek to organise their childcare work to support the wellbeing of childminders' own family members: narratives described adaptations made in order to ensure that their own children's acceptance of the service. For example, one childminder felt her school age children were missing out due to the service; as a result, she reduced her number of working days a to allow her own children have schoolmates home after school one day a week.

While no participant referred to themselves as a substitute mother, some childminders described their role in terms of "rearing children." Several mentioned the 
responsibility of the length of time minded children spent with them in terms of shaping the children's values, as the following extract illustrates:

I feel I'm rearing a lot of these children. And they're picking up traits from me and my children, and some of them are with me, like eight hours a day... It's just very rewarding knowing I'm putting something into their... their future. -Sonia.

In addition, participants mentioned the benefits of mixed age groups for siblinglike interactions as well as highlighting the benefits for siblings of being together, as this description shows:

And I picked (this photo), because ...there were siblings in it, that they're kept together, and they have another little one here as well. That they're all, they're not in a different room, or a different part, they're together. -Marianne.

An interesting feature of the children's relationships was their mixed ages, which offered diverse opportunities for learning and development, permitting children to learn from older and younger playmates as well as their peers (Gray 2011). Participants also mentioned how childminding created a bigger family for isolated or lone children, as in this quote: "My children don't have really like, yeah, a sibling, they're just two. So, they feel when they have these children, 'I have a little sister. I have a little brother."' - Cynthia.

Findings also revealed that many childminders attended the family celebrations of minded children, such as birthday parties, communions, and even parents' weddings. Such involvement in family rituals has the potential to reinforce the sense of identity and belonging for children, through these respectful relationships between families within their broader communities (NCCA 2009).

Since the family home was used for the service, all childminders in the study emphasised the importance of family support for the childminding service, whether that 
was their husband/partner, children, or extended family members. Spouses/partners, adult children, the childminders' parents and other relatives helped with school runs, food purchase and preparation, or just playing with children while the childminder attended to one particular child, if needed. Some spouses/partners became part of the children's lives, particularly if they worked from home, as some did:

My husband is here probably three days a week. ... So, he's finished work by four o'clock. ... if I'm going out with the lads and the girls, he might come with me, and we'll bring the dog and he'll do a kick around with the lads. - Jill

While participants all acknowledged family acceptance and support as vital in running a childcare service, the converse was also true. For some, the enmeshment of work life and family posed the greatest challenge and could lead to the eventual closure of the service.

\section{Discussion}

Drawing from cultural approaches to human development, daily life is understood as embedded in a local setting (Weisner \& Bernheimer, 2004), variously viewed as a microsystem (Bronfenbrenner and Morris 2006), or an ecocultural niche (Tonyan 2015, 2017). Tonyan and Nuttall offer the following definition of a childminding service as "a home-based ecological niche in which multiple families (i.e. childminder, children, childminder's own family, children's families and assistants) negotiate the project of raising children" $(2014,119)$. In certain ways, the childminding services involved in this study were more proximate than those in California to this ecocultural definition.

Firstly, childminding services in this study were family-sized, with no more than six children in a group, as per the planning laws (Dept. of the Environment 2015): similar to group sizes in childminding across Europe (Boogaard, Bollen, and Dikkers 
2013), where small group size has been linked to higher process quality (Laevers et al. 2016). These settings could more easily form a closely knit "home-based ecological niche of multiple families" (Tonyan and Nuttall 2014, 119), than the larger groups in California, where a large-scale licence allows up to 14 children with an assistant. This structural parameter had a significant impact on childminders' distinctive Close Relationship Model of praxis in this study.

Secondly, these childminding services constituted an ecological niche where parents choose a childminder who espouses similar beliefs, core values and cultural models in order to "work together in raising children" (ibid., 119). Since nearly all childminders in the present study were parents, many with young children, they cooperated with other families by providing activities which the client parent would do themselves, if they were at home with the child. In practical terms, one set of parents provide the financial means to a childminding parent, which allows her to remain in the home to raise her own child(ren), while s/he provides the minded children with the kind of upbringing these parents desire.

In this ecological context, a significant finding was the extent to which concepts of attachment theory, such as attunement and sensitivity, informed childminders' conceptualisation of the childminder-child relationships, becoming a feature of the Close Relationship Model identified in terms of understanding love, affection, and fun as well as the centrality of interactions to child development. Narratives confirmed previous findings on attunement growing with daily interactions in intimate care, in play, and other routines (Dalli et al. 2011; Trevarthen and Delafield-Butt 2017). Such attunement is facilitated by time in relaxed, unhurried home environments, with relatively low stress as a result small group size, high adult-child ratio, and consistent, stable relationships between childminders, children and families (Ang, Brooker, and 
Stephen 2016; Groeneveld et al. 2010). Attunement is also linked to children's outcomes: a meta-analysis of 40 investigations by the NICHD (Ahnert, Pinquart, and Lamb 2006) found that US caregivers' sensitivity to individual children in home-based settings predicted individual attachment security, while Groeneveld et al. (Groeneveld et al. 2010) found that higher caregiver sensitivity among childminders was positively associated with children's wellbeing.

\section{The Close Relationships Model in Ireland}

Consistent with findings in the study in California, in this cultural model, the childminder's primary goal is for each child to feel loved and special. The childminder prioritises showing love and affection to children, interacting with the children through play and conversation, and building relationships through these interactions. The Close Relationships childminder frequently talks about the strong relationships with children who are or who have been in their care and mentions it as one of the rewarding aspects of the role (CCCRP, 2014; Tonyan, 2017). However, the Close Relationship Model described in this study goes beyond that specified by Tonyan and Nuttall, regarding the enduring nature of the relationships and the conceptualisation of the service as extended family, on which the remainder of this discussion will focus.

A striking finding in the Irish context, not found in the Californian study, was the depth and longevity of childminding relationships, both outside of childcare hours and long after the childcare arrangement had ceased in some cases, a finding not previously identified in childminding research. Narratives revealed that the emotional bonds were not experienced as temporary or passing attachments, but rather as lasting and enduring (Bowlby, 2007). While maternal experience was drawn upon in the formation of these enduring bonds with children, childminding love was carefully 
differentiated to support and not replace the mother in a child's life (Page 2011, 2018). It was also understood as vital to build and maintain a close working relationship with parents.

Theorizing professional love in ECEC, Page maintains that "Deep, sustaining, respectful and reciprocal relationships between adults and children are vital for children's holistic development." $(2011,312)$. In recent years however, discussion of love, affection and care in early years has tended to be displaced by discourses of dispassionate professionalism, underpinned by scientific knowledge of child development and pedagogy, separated from caring roles (Brock 2013; Van Laere, Peeters, and Vandenbroeck 2012), and freed from "the image that only 'maternal' skills and competencies are important for a job in childcare" (Peeters 2007, 7). This is a challenge for childminders and centre-based practitioners alike, as irrespective of setting, it could be argued that research into positive child development and learning supports the need for adults in caring roles to be anything but dispassionate (CampbellBarr 2018). A nurturing pedagogy sees relationships between adults and children as central to both care and education, as Hayes et al. $(2007,2008)$ argue: caring is educative.

Another noteworthy new finding was the conceptualisation of childminding in terms of extended family relationships, in which both the child, and the family were included. This is particularly important for young children and families in changing Irish society where smaller family size and increasing family mobility due to employment can leave young families isolated, far from familial networks (Garrity and Canavan 2017). Richard Bowlby (2007) has highlighted how childminders develop a type of secondary attachment relationship with children, resembling the relationship a child might have with grandparents. Thinking in such terms, childminders viewed the 
minded children as if they were relatives, such as nephews and nieces and facilitated the mixed age group as if they were cousins. They welcomed interactions with the older generation, and participated in children's milestone celebrations, as would a relative. Similarly, considerable importance was ascribed to keeping siblings together in the same group for both childminders and families, consistent with previous research identifying sibling grouping as one of the perceived benefits of childminding (Davis, Freeman, et al., 2012).

One noteworthy finding concerned the mixed age groups, which offered unique opportunities for socialising among a small group of children, stimulating the development of younger children, and promoting empathy and responsibility in older ones, not unlike cousins within an extended Irish family (Ní Laoire 2014, 2011). Study participants revealed innovative praxis in relation to managing the dynamic of such mixed age groups to maximise its opportunities for scaffolding, maturation and relational development for the children involved, in an example of experiential knowledge, which should be reintegrated into our understandings of the knowledge base of early years workers (Campbell-Barr, Georgeson, and Nagy Varga 2015)

A further familial aspect of childminding is intergenerational: members of childminders' own extended families, such as parents or aunts, were sometimes involved in supporting childminding provision, providing significant interactions for very young children, for whom they become surrogate grandparents. Interactions between young and old are especially appreciated in a country that has retained a strong sense of community (Gallagher and Fitzpatrick 2017; Fitzpatrick 2019). This may derive partially from a Catholic cultural ethos of mutual support within families (Bromer and Henly 2004; Cohen and Hill 2007) as could participation in milestone 
family and community events (Inglis 2007), similar to findings from an ecocultural study of Latinx childminders in Los Angeles (Paredes et al. 2018).

\section{Implications for policy}

The interface between private and public in childminding services poses a dilemma for public policy in every jurisdiction as it concerns more than just the professionalism of a childminder, it concerns a whole family in a home, and sometimes member of the extended family also. To be sustainable, any proposed new national system of regulation, support, and education for childminders in Ireland will have to be aligned with childminders' cultural models if it is to prove meaningful, congruent and sustainable for childminders and families, and maximise its benefits for children.

To engage childminders effectively, childminding regulations need to be developed, which are aligned with childminding ecoculture, in terms of respecting the homeliness of the family home, recognising the benefits of these small, intimate services for children, and the dual roles of the professional childminder as a parent working in the family home. Alongside childminding inspections, there is need for supportive supervision of childminders' emotional well-being in their practice of professional love.

In addition, childminder education must be developed that facilitates current childminding praxis, aligned with occupational standards derived from Irish cultural models, such as the Close Relationships Model, in terms of content. Consideration must also be given to accessible, relationship driven modes of delivery for childminders who work long hours alone and in relative isolation.

To engage childminders effectively, it is vital that any proposed national system of regulation be well aligned with local cultural models, if it is to prove sustainable for 
childminders, parents and families, and maximise the benefits of childminding for children's outcomes. 


\section{Bibliography}

Ahnert, Lieselotte, Martin Pinquart, and Michael E Lamb. 2006. 'Security of Children's Relationships With Nonparental Care Providers' Child Development 74 (3): 664-79. https://doi.org/10.1111/j.1467-8624.2006.00896.x.

Ang, Lynn, Elizabeth Brooker, and Christine Stephen. 2016. 'A Review of the Research on Childminding: Understanding Children's Experiences in Home-Based Childcare Settings'. Early Childhood Education Journal 45 (2): 1-10. https://doi.org/10.1007/s10643-016-0773-2.

Bauters, Valerie, and Michel Vandenbroeck. 2017. 'Bauters \& Vandenbroeck The Professionalisation of Family Day Care in Flanders France and Germany'. European Early Childhood Education Research Journal. https://doi.org/10.1080/1350293X.2017.1308164.

Boogaard, Marianne, Iris Bollen, and Liselotte Dikkers. 2013. 'Gastouderopvang in West-Europese Landen'.

Bowlby, John. 1969. Attachment and Loss: Attachment. Attachment. Vol. 1. https://doi.org/10.1177/000306518403200125.

- 1984. Attachment and Loss, Vol. 3. Loss, Sadness and Depression. Vol. 32. https://doi.org/10.1177/000306518403200125.

Bowlby, John. 1988. A Secure Base : Clinical Applications of Attachment Theory. Routledge.

Bowlby, Richard. 2007. 'Babies and Toddlers in Non-Parental Daycare Can Avoid Stress and Anxiety If They Develop a Lasting Secondary Attachment Bond with One Carer Who Is Consistently Accessible to Them'. Attachment \& Human Development 9 (4): 307-19. https://doi.org/10.1080/14616730701711516.

Brock, Avril. 2013. 'Building a Model of Early Years Professionalism from Practitioners' Perspectives'. Journal of Early Childhood Research 11 (1): 27-44. https://doi.org/10.1177/1476718X12456003.

Bromer, Juliet, and Julia R. Henly. 2004. 'Child Care as Family Support: Caregiving Practices across Child Care Providers'. Children and Youth Services Review 26 (10): 941-64. https://doi.org/10.1016/j.childyouth.2004.04.003.

Bromer, Juliet, Lisa A. McCabe, and Toni Porter. 2013. 'Special Section on Understanding and Improving Quality in Family Child Care: Introduction and Commentary'. Early Childhood Research Quarterly 28 (4): 875-78. https://doi.org/10.1016/j.ecresq.2013.08.003.

Bronfenbrenner, U, and P A Morris. 2006. 'The Bioecological Model of Human Development'. Handbook of Child Psychology 1: 793-828. https://doi.org/10.1002/9780470147658.chpsy0114.

Brooker, Liz. 2016. 'Childminders, Parents and Policy: Testing the Triangle of Care'. Journal of Early Childhood Research 14: 69-83. https://doi.org/10.1177/1476718X14548779.

Campbell-Barr, Verity. 2018. 'The Silencing of the Knowledge-Base in Early Childhood Education and Care Professionalism'. International Journal of Early Years Education, 2018. https://doi.org/10.1080/09669760.2017.1414689.

Campbell-Barr, Verity, Janet Georgeson, and Anikó Nagy Varga. 2015. 'Developing Professional Early Childhood Educators in England and Hungary: Where Has All the Love Gone?' European Education 47 (4): 311-30. https://doi.org/10.1080/10564934.2015.1100451.

CCCRP. 2014. The Ecocultural Family Interview For Family Child Care Providers.

CECDE. 2006. 'Síolta. The National Quality Framework for Early Childhood Education', no.April: 1-19.

Child in Mind. 2017. 'Child In Mind Evidence-Based Learning Outcomes for Informal Childminders'.

Cohen, Adam B., and Peter C. Hill. 2007. 'Religion as Culture: Religious Individualism and Collectivism among American Catholics, Jews, and Protestants'. Journal of Personality. Blackwell Publishing, Inc. https://doi.org/10.1111/j.1467-6494.2007.00454.x.

Cole, Michael. 1998. 'Can Cultural Psychology Help Us Think About Diversity?' Mind, Culture and Activity 5 (4): 291-304. https://doi.org/10.1207/s15327884mca0504.

CSO. 2017. 'CSO Quarterly National Household Survey Module on Childcare2017'.

Dalli, C., E.J. White, J. Rockel, I. Duhn, E. Buchanan, S. Davidson, S. Ganly, L. Kus, and B. Wang. 2011. Quality Early Childhood Education for Under-Two-Year-Olds : What Should It Look like? A Literature Review.

Daly, Mary. 2010. 'An Evaluation of the Impact of the National Childminding Initiative on the Quality of Childminding in Waterford City and County.' Waterford City \& County Childcare Committees, and Health Service Executive South.

Davis, Elise, Ramona Freeman, Gillian Doherty, Malene Karlsson, Liz Everiss, Jane Couch, Lyn Foote, et al. 2012. 'An International Perspective on Regulated Family Day Care Systems'. Australasian Journal of Early Childhood, no. December.

DCYA. 2016. CHILD CARE ACT 1991 (EARLY YEARS SERVICES) REGULATIONS 2016. Department of Children and Youth Affairs. Vol. 1991. 
2018a. 'Pathway to a Quality Support \& Assurance System for Childminding: Summary Report of the Working Group on Reforms and Supports for the Childminding Sector'.

2018b. Registration of School Age Services.

2019. 'Draft Childminding Action Plan August 2019'.

Dept. of the Environment. 2015. Planning and Development Regulations 2001-2015. https://doi.org/10.1017/CBO9781107415324.004.

Fitzpatrick, Anne. 2019. 'Towards a Pedagogy of Intergenerational Learning.' In Intergenerational Learning in Practice: Together Old and Young, edited by Margaret Kernan and Giulia Cortellesi.

Gallagher, Carmel, and Anne Fitzpatrick. 2017. 'Intergenerational Learning in Preschool and Elder Care Settings: An Irish Perspective'. Journal of Intergenerational Relationships 16: 1-2. https://doi.org/10.1080/15350770.2018.1404403.

Garrick, Ros, Caroline Bath, Karen Dunn, Heloise Maconochie, and Ben Willis. 2010. 'Children's Experiences of the Early Years Foundation Stage', no. December: 1-9.

Garrity, Sheila, and John Canavan. 2017. 'Trust, Responsiveness and Communities of Care: An Ethnographic Study of the Significance and Development of Parent-Caregiver Relationships in Irish Early Years Settings'. European Early Childhood Education Research Journal 0 (0): 1-21. https://doi.org/10.1080/1350293X.2017.1356546.

Garrity, Sheila, and Brian McGrath. 2011. "It's Not like a Job Now; It's Part of Me": Exploring African Women's Experiences in the Irish Childcare Sector'. Child Care in Practice 17 (1): 69-86. https://doi.org/10.1080/13575279.2010.522977.

Gillen, Julia. 2014. "" A Day in the Life ": An International Study of Two-Year-Old Girls and Their Families " A Day in the Life ": An International Study of Two-Year-Old', no. September 2014.

Gillen, Julia, Catherine Ann Cameron, Sombat Tapanya, Giuliana Pinto, Roger Hancock, Susan Young, and Beatrice Accorti Gamannossi. 2007. "A Day in the Life": Advancing a Methodology for the Cultural Study of Development and Learning in Early Childhood'. Early Child Development and Care 177 (2): 207-18. https://doi.org/10.1080/03004430500393763.

Govt. of Ireland. 2019. ‘A Whole-of-Government Strategy for Babies, Young Children and Their Families', 1-196.

Groeneveld, Marleen G., Harriet J. Vermeer, Marinus H. van IJzendoorn, and Mariëlle Linting. 2010. 'Children's Wellbeing and Cortisol Levels in Home-Based and Center-Based Childcare'. Early Childhood Research Quarterly 25 (4): 502-14. https://doi.org/10.1016/j.ecresq.2009.12.004.

Harkness, Sara, Charles M. Super, and Natalie van Tijen. 2000. 'Individualism and the "Western Mind" Reconsidered: American and Dutch Parents' Ethnotheories of the Child.' New Directions for Child \& Adolescent Development 2000 (87): 23-39. https://doi.org/10.1002/cd.23220008704.

Holland, Dorothy C., and Naomi Quinn. 1987. Cultural Models in Language and Thought. Cambridge University Press.

Inglis, Tom. 2007. 'Catholic Identity in Contemporary Ireland : Belief and Belonging to Tradition'. Journal of Contemporary Religion 22 (2): 205-20.

Kernan, M, and D. Devine. 2010. "“Being Confined within?" Constructions of a "Good” Childhood and Outdoor Play in Early Childhood Education and Care Settings in Ireland,'. Children and Society, 24 (5): 386-400.

Koch, Anette Boye. 2018. 'Children's Perspectives on Happiness and Subjective Well-Being in Preschool'. Children and Society 32 (1): 73-83. https://doi.org/10.1111/chso.12225.

Kontos, Susan, Carollee Howes, Marybeth Shinn, and Ellen Galinsky. 1995. Quality in Family Child Care and Relative Care. Early Childhood Education Series. Early Childhood Education Series. Teachers College Press.

Laere, Katrien Van, Jan Peeters, and Michel Vandenbroeck. 2012. 'The Education and Care Divide: The Role of the Early Childhood Workforce in 15 European Countries'. European Journal of Education 47 (4): 527-41. https://doi.org/10.1111/ejed.12006.

Laevers, Ferre, Evelien Buyse, Mieke Daems, and Bart Declercq. 2016. 'Welbevinden En Betrokkenheid Als Toetsstenen Voor Kwaliteit in de Kinderopvang. Implicaties Voor Het Monitoren van Kwaliteit'. BKK.

Letablier, Marie-Thérèse, and Jeanne Fagnani. 2009. 'EUROPEAN ALLIANCE FOR FAMILIES European Expert Group on Demography Best Practice Meeting on Child Care by Child Minders in France Childminders in the French Childcare Policy'.

Mooney, A, and J Statham. 2003. Family Day Care. International Perspectives on Policy, Practice and Quality. Edited by Ann Mooney and June Statham.

Mooney, Ann, Peter Moss, Charlie Owen, Ann Mooney, Peter Moss, and Charlie Owen. 2001. 'A Survey of Former Childminders'.

Morrissey, Taryn W, and Patti Banghart. 2007. 'Family Child Care in the United States'. Childcare and 
Early Education Research Connections.

NCCA. 2009. Aistear: The Early Childhood Curriculum Framework.

Nelson, Margaret K. 1990. 'Mothering Others' Children: The Experiences of Family Day-Care Providers'. Signs: Journal of Women in Culture and Society 15 (3): 586-605. https://doi.org/10.1086/494611.

Ní Laoire, Caitríona. 2011. 'Narratives of "Innocent Irish Childhoods": Return Migration and Intergenerational Family Dynamics'. Journal of Ethnic and Migration Studies 37 (8): 1253-71. https://doi.org/10.1080/1369183X.2011.590928.

. 2014. 'Children, Cousins and Clans: The Role of Extended Family and Kinship in the Lives of Children in Returning Irish Migrant Families'. In The 'Irish' Family, edited by Linda Connolly, $140-58$.

Page, Jools. 2011. 'Do Mothers Want Professional Carers to Love Their Babies?' Journal of Early Childhood Research 9 (3): 310-23. https://doi.org/10.1177/1476718X11407980.

- 2018. 'Characterising the Principles of Professional Love in Early Childhood Care and Education'. International Journal of Early Years Education 26 (2): 125-41. https://doi.org/10.1080/09669760.2018.1459508.

Paredes, Elena, Edgar Hernandez, Alice Herrera, and Holli Tonyan. 2018. 'Putting the "Family" in Family Child Care: The Alignment between Familismo (Familism) and Family Child Care Providers' Descriptions of Their Work'. Early Childhood Research Quarterly. https://doi.org/10.1016/j.ecresq.2018.04.007.

Peeters, Jan. 2007. 'The Construction of a New Profession : A European Perspective on Professionalism in ECEC The Construction of a New Profession : Professionalism in Flemish Childcare'.

Rogoff, B., L. Moore, B Najafi, a Dexter, M Correa-Chavez, and J Solis. 2007. 'Childrens Development of Cultural Repertoires through Participation in Everyday Routines and Practices'. Handbook of Socialization: Theory and Research, no. 2007: 490-515.

Rogoff, Bárbara. 2003. The Cultural Nature of Human Development. Oxford University Press.

Salmona, M, E Lieber, and D Kaczynski. 2019. Qualitative and Mixed Methods Data Analysis Using Dedoose. Sage Publications.

Sroufe, L Alan. 2005. 'Attachment and Development: A Prospective, Longitudinal Study from Birth to Adulthood'. Attachment and Human Development 7 (4): 349-67. https://doi.org/10.1080/14616730500365928.

Start Strong. 2012. 'Childminding : Regulation and Recognition', no. October: 1-4.

Strauss, Diana, and Anita Cooper. 2012. 'Narratives from the Nursery. Negotiating Professional Identities in Early Childhood . By J. Osgood'. British Journal of Educational Studies 60 (3): 285-87. https://doi.org/10.1080/00071005.2012.714548.

Tonyan, Holli A. 2012. 'Understanding Home- - Based Care as a Culturally Organized Ecological Niche : Cultural Models and the Organization of Daily ... Understanding Home- - - Based Care as a Culturally Organized Ecological Niche'?: https://doi.org/10.13140/2.1.1468.5120.

Tonyan, Holli A., Diane Paulsell, and Eva Marie Shivers. 2017. 'Understanding and Incorporating HomeBased Child Care Into Early Education and Development Systems'. Early Education and Development 28 (6): 633-39.

Tonyan, Holli A. 2015. 'Everyday Routines: A Window into the Cultural Organization of Family Child Care'. Journal of Early Childhood Research 13 (3): 311-27. https://doi.org/10.1177/1476718X14523748.

- 2017. 'Opportunities to Practice What Is Locally Valued: An Ecocultural Perspective on Quality in Family Child Care'. Early Education and Development. https://doi.org/10.1080/10409289.2017.1303304.

Tonyan, Holli A, and Joce Nuttall. 2014. 'Connecting Cultural Models of Home-Based Care and Childminders' Career Paths: An Eco-Cultural Analysis'. International Journal of Early Years Education 22 (1): 117-38. https://doi.org/10.1080/09669760.2013.809654.

Trevarthen, Colwyn, and Jonathan T. Delafield-Butt. 2017. 'Intersubjectivity in the Imagination and Feelings of the Infant: Implications for Education in the Early Years'. In Under-Three Year Olds in Policy and Practice, edited by E. J. White and C. Dalli. https://doi.org/10.1007/978-981-10-2275-3.

Urban, Mathias, Michel Vandenbroek, Arianna Lazzari, Jan Peeters, and Katrien van Laere. 2011. 'Competence Requirements in Early Childhood Education and Care (CoRe) Final Report'.

Weisner, Thomas S. 1997. 'The Ecocultural Project of Human Development: Why Ethnography and Its Findings Matter'. Ethos 25 (2): 177-90. https://doi.org/10.1525/eth.1997.25.2.177.

Weisner, Thomas S., and Lucinda P. Bernheimer. 2004. 'Sustainablity of Daily Routines as a Family Outcome'. In Learning in Cultural Context: Family, Peers and School, edited by Ashley Maynard and Mary Martini. New York: Kluwer/Plenum. https://doi.org/10.1007/0-387-27550-9. 
Weisner, Thomas S., and C. M. Hay. 2015. 'Practice to Research: Integrating Evidence-Based Practices with Culture and Context'. Transcultural Psychiatry 52 (2): 222-43. https://doi.org/10.1177/1363461514557066.

Weisner, Thomas S. 2002. 'Ecocultural Understanding of Children's Developmental Pathways'. Human Development 1759: 275-81.

. 2014. 'Why Qualitative and Ethnographic Methods Are Essential for Understanding Family Life'. In Emerging Methods in Family Research, edited by S. M. McHale. Vol. 4.

https://doi.org/10.1007/978-3-319-01562-0. 